\title{
MANAJEMEN GETARAN UNTUK KESETABILAN LERENG DENGAN METODE "SIGNATURE HOLE ANALISYS" DALAM KEGIATAN PELEDAKAN TAMBANG TERBUKA
}

\author{
Muhammad Syafiq Isnaya ${ }^{\text {() }}$, Fadhil Bellico ${ }^{2)}$, dan Dwi Agung Priyanggoro ${ }^{3)}$ \\ ${ }^{1,2)}$ Technical Service Department, PT. Multi Nitrotama Kimia \\ ${ }^{3)}$ Engineering Department, PT. Alamjaya Bara Pratama
}

\begin{abstract}
ABSTRAK
Pit 10 merupakan wilayah operasional PT. Alamjaya Bara Pratama dalam kegiatan peledakan bekerjasama dengan PT. Multi Nitrotama Kimia sebagai penyedia bahan peledak dan jasa peledakan. Salah satu dampak yang ditimbulkan dari kegiatan peledakan adalah Ground Vibration yang akan mempengaruhi kestabilan lereng pada area pit 10 . Desain akhir lereng pada pit 10 menunjukan batas maksimal Peak Particle Acceleration $\left(\mathrm{a}_{\max }\right.$ ) yang dapat diterima lereng akibat hasil peledakan sebesar $0,07 \mathrm{~g}$, sehingga perlu adanya manajemen getaran agar getaran yang dihasilkan oleh kegiatan peledakan tidak mempengaruhi kestabilan lereng di area Pit 10. Penelitian dan percobaan dilakukan menggunakan metode Signature Hole Analysis (SHA) untuk pemetaan terhadap perambatan gelombang di setiap range blok - strip tertentu untuk kemudian digunakan untuk memodelkan dan memprediksi getaran yang diakibatkan oleh kegiatan peledakan pada setiap blok - strip. Metode Signature Hole Analysis yang dikombinasikan dengan pendekatan Scaled Distance, berhasil menjadi solusi dalam tata kelola getaran peledakan di Pit 10. Hasilnya, sepanjang tahun 2019 berjalan, tidak ada isu berkenaan dengan bagian geoteknik dari lereng-lereng di seputaran area operasional Pit 10. Pendekatan Signature Hole Analysis dan kontrol bersama tim Geoteknik menghasilkan kerjasama yang baik serta tata kelola kestabilan lereng menjadi lebih aman.
\end{abstract}

Kaca Kunci : Kestabilan Lereng, Peledakan, Signature Hole Analysis

\begin{abstract}
Pit 10 is operational area of PT. Alamjaya Bara Pratama the blasting activity carried out with PT. Multi Nitrotama Kimia as provider of explosive and blasting service. One of the impact blasting activity is Ground Vibration which will affect the stability of the slope in the area pit 10. The final slope design in pit 10 shows the maximum limit of peak particle acceleration $\left(a_{\max }\right)$ that can't be exceed by $0,07 \mathrm{~g}$. its very necessary to manage the ground vibration so the vibration produced by blasting activity do not affect the stability of the slope in pit 10. Research and experiment conducted using Signature Hole Analysis (SHA) for monitoring wave propagation in each blockstrip used to model and predict vibration which caused by the blasting activity. Signature Hole Analysis combined with Scaled Distance has succeeded in becoming the solution of ground vibration management in pit 10. Throughout 2019 there was no problem with geotechnical issues of slopes around the pit 10. Signature Hole Analysis Method and Geotechnical approachment result good impact of a slope stability on pit 10.
\end{abstract}

\section{A. PENDAHULUAN}

\section{A.1. Latar Belakang}

PT Multi Nitrotama Kimia merupakan salah satu perusahaan jasa pertambangan yang bergerak pada bidang penyedia jasa peledakan dan penjualan bahan peledak terbesar di Indonesia. Unit 
usaha ini bekerjasama dengan berbagai perusahaan pertambangan di Indonesia, salah satunya adalah PT. Alam Jayabaya Pratama. Kerjasama yang terjalin anatara dua perusahaan ini adalah untuk layanan blasting Service atau yang lebih dikenal dengan istilah TLBS (Total Load Blasting service). Area operasional penambangan perusahaan ini berada di Provinsi Kalimantan Timur (Gambar 1) yang terdiri dari 3 (Tiga) Pit, yaitu : Pit 7 Utara, Pit 8 dan Pit 10.

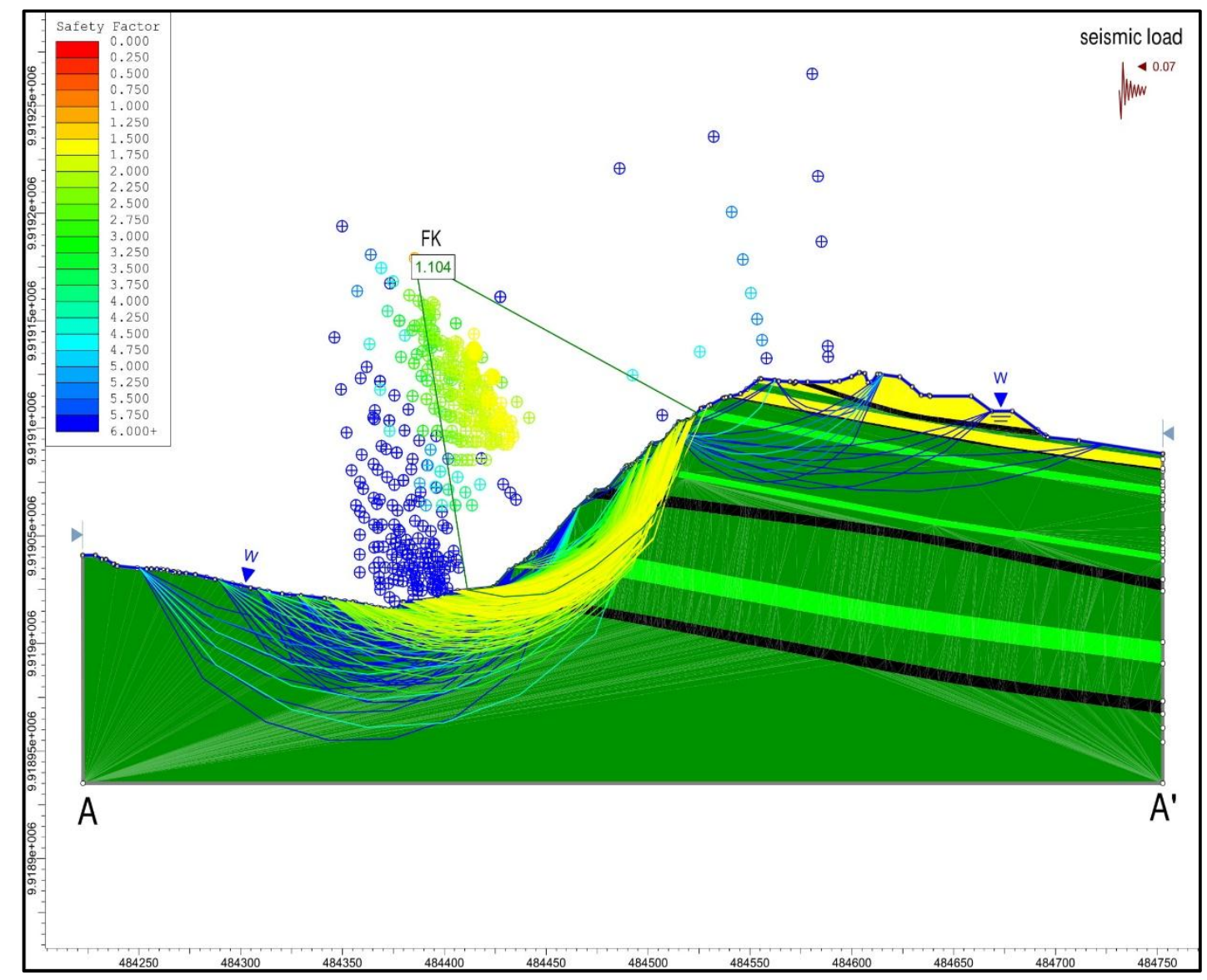

Gambar 1. Desain Akhir Lereng pada pit 10

Salah satu dampak kegiatan peledakan pada pit 10 adalah ground vibration yang akan mempengaruhi kesetabilan lereng pada area pit 10. Pada kegiatan peledakan, hanya sebagian dari total energi yang dihasilkan bahan peledak dikonsumsi untuk memecahkan batuan, sementara sisnya menjadi waste energy atau energy sisa yang dapat mempengaruhi kestabilan lereng. Energi peledakan yang menyebabkan elastic deformation dapat menghasilkan stress waves (body wave) yang merambat melalui massa batuan . Energi yang tersisa (Seismic energy) akan menjalar melalui batuan mengakibatkan deformasi dalam batuan tetapi tidak memecahkan batuan, karena masih di dalam batas elastiknya. Desain akhir dari pit 10 menunjukan batas maksimal Peak Particle Acceleration (Seismic Load) yang dapat diterima oleh lereng sebesar $0,07 \mathrm{~g}$, sehingga perlu adanya manajemen getaran sehingga getaran yang dihasilkan oleh kegiatan peledakan tidak mempengaruhi kestabilan lereng di Pit 10 (Gambar 2).

\section{A.2. Tujuan Perbaikan}

Penelitian ini dilakukan untuk pemetaan terhadap perambatan gelombang di setiap range blokstrip tertentu kemudian digunakan untuk memodelkan dan memprediksi getaran yang diakibatkan oleh kegiatan peledakan pada setiap blok - strip, sehingga keluaran yang dihasilkan dari berbentuk rekomendasi isian berdasar jarak lokasi peledakan dengan lereng pada pit 10. Dengan adanya 
permodelan getaran maka energi yang tersisa (Seismic energy) akibat aktifitas peledakan dapat di prediksi agar Peak Particle Acceleration tidak melebihi ambang batas yang ditetapkan.

\section{A.3. Problem Analysis}

Ada beberapa tahapan proses pada siklus peledakan yang perlu dijadikan fokus dalam mencari masalah pada kasus getaran tanah akibat peledakan, yaitu : Planning, Charging Tie Up \& Monitoring. Dalam kasus yang terjadi sepanjang 2019, di dominasi oleh adanya masalah pada perencanaan. Dimana perencanaan yang dibuat untuk mengendalikan getaran peledakan tidak berhasil saat diterapkan di lapangan sehingga menyebabkan kestabilan lereng pada area pit 10 terganggu. Kontrol getaran tanah pada peledakan di Pit 10 menggunakan hubungan jumlah isian bahan peledak per waktu tunda dengan nilai getaran yang dihasilkan.

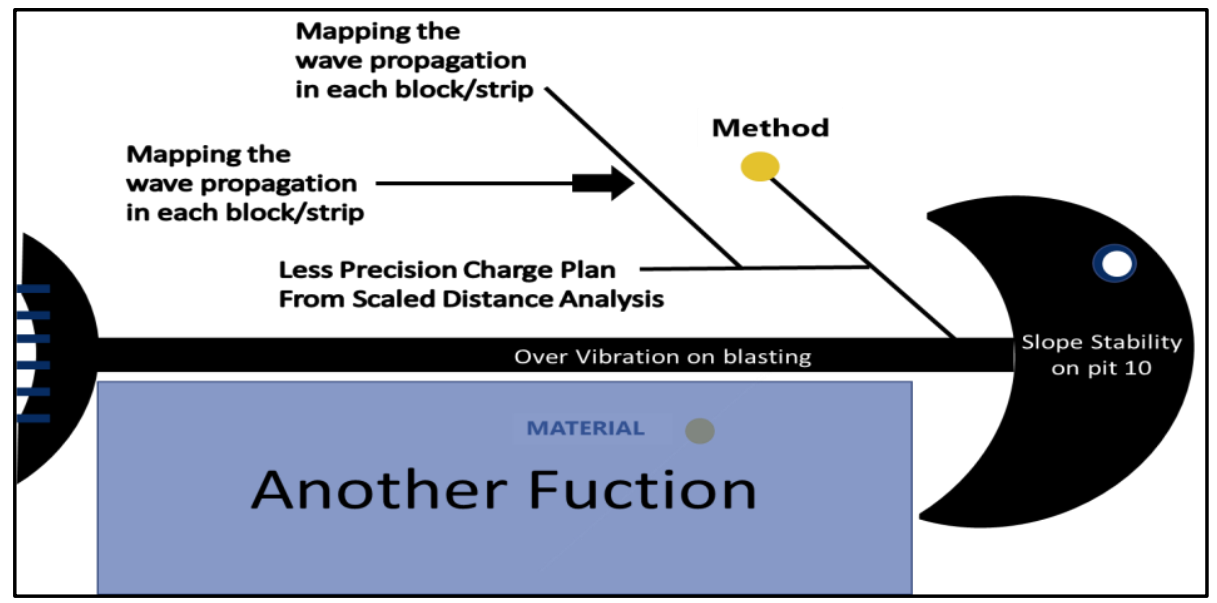

Gambar 2. Fish-bone Analysis unuk masah kestabilan lereng pit 10

Ketidaktepatan dalam pendekatan dalam persamaan Scaled Distance Analysis dipengaruhi oleh kondisi geologi, dalam hal ini adalah sebagai media rambat getaran. Sehingga pemetaan terhadap gambaran kondisi tambatan gelombang di setiap blok/strip tertentu yang mewakili kondisi geologi (Gambar 2.)

\section{B. PERBAIKAN (IMPROVEMENT)}

\section{B.1. Mapping Area}

Terdapat struktur mayor pada pit 10 dimana aktifitas peledakan yang digunakan untuk memberai massa batuan berlangsung, unutk kemudian dijadikan titik pengambilan data rambatan gelombang getaran tanah. Posisi blok-strip ini menjadi focus perhatian dala penentuan pengambilan data gelombang getaran tanah karena memiliki potensi anomaly gelombang yang relatif tinggi.

\section{B.2. Pemodelan Rambat Gelombang dengan Signature Hole Analysis}

Mengacu pada Problem Analysis fokus perbaikan untuk masalah kestabilan lereng terganggu akibat peledakan di pit 10 adalah melakukan pemetaan terhadap setiap blok/strip tertentu yang mewakili kondisi geologi dengan menggunakan metode Signature Hole Analysis (SHA). Hasil data rambatan gelombang per blok/ strip tersebut kemudian akan diolah ke dalam Scaled Distance Analysis.

Signature Hole Analysis (SHA) adalah suatu analisa yang dilakukan untuk merekam gelombang daru satu atau banyak lubang ledak standar. Sensor getaran yang ditempatkan diantara tempat yang sensitif terhadap getaran, yaitu dinding, bangunan, bendungan (Gambar 3). Hal ini akan memberikan informasi mengenai homogenitas masa batuan dengan rekaman rambat gelombang getaran yang dihasilkan dan ditangkap oleh alat ukur. 


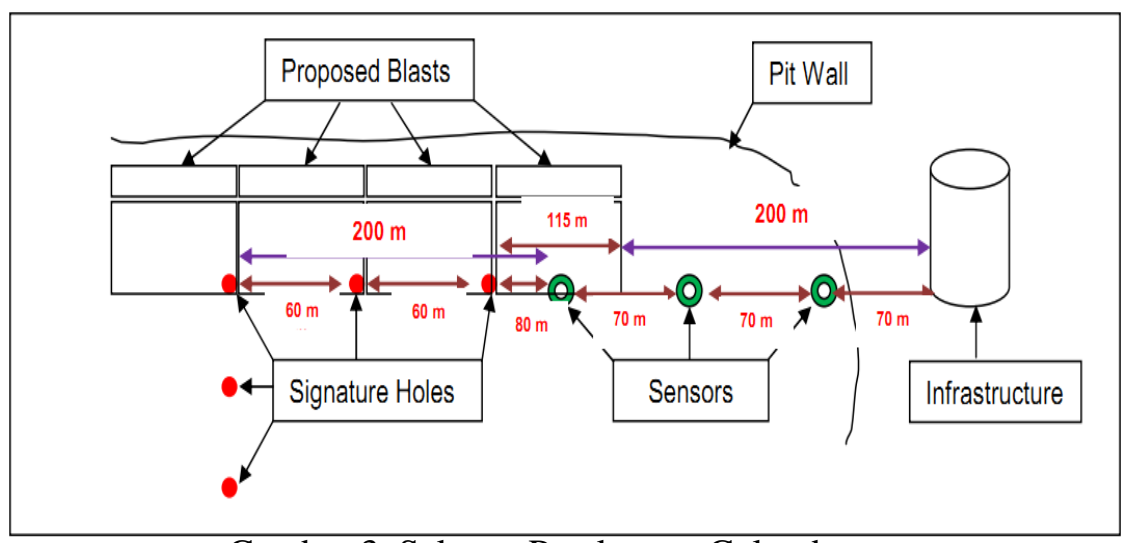

Gambar 3. Sekema Perekaman Gelombang

Pelaksanaan Signature Hole Analysis yang dilakukan menggunakan 5 lubang sejajar dengan arah direct-initiation nya mengarah ke lereng pada low wall Pit 10. Untuk pengukuranya menggunakan alat ukur getaran dan kebisingan. Alat perekam diletakkan tegak lurus dengan lereng pada low wall pit 10 dengan cakupan jarak 100-300m terhadap lubang Signature Hole Analysis terakhir (Gambar 4.)

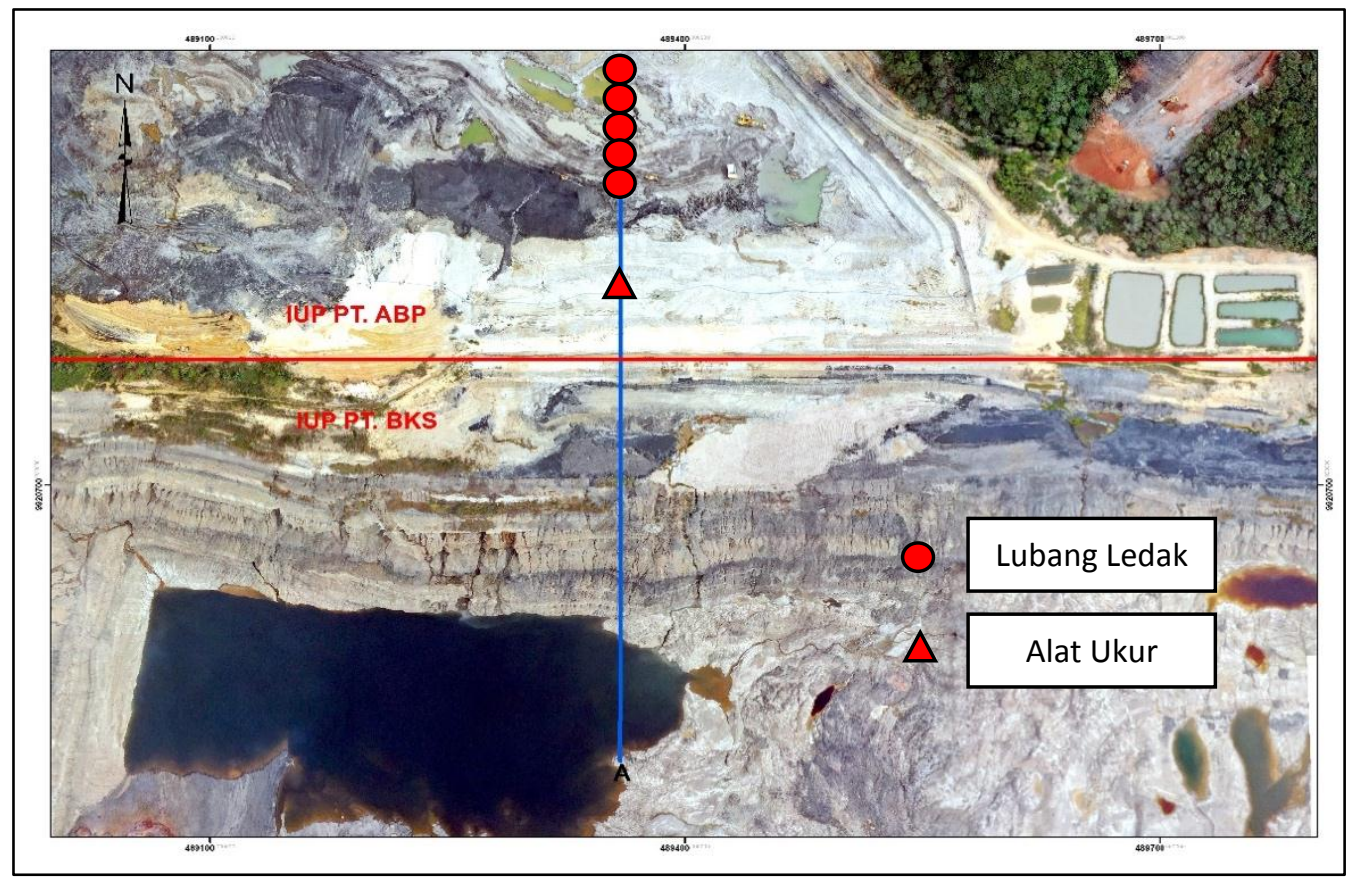

Gambar 4.. Desain Pelaksanaan Signature Hole Analysis

Dalam improvement ini output nya adalah record "background" Vibration (informasi terkait dengan gambaran media rambat sekitar) digunakan sebagai alat untuk mendapatkan gambaran kondisi rambatan gelombang pada setiap strip/blok sehingga keluaran yang dihasilkan dari Signature Hole Analysis ini berbentuk rekomendasi isian berdasar jarak lokasi peledakan dengan lereng pada pit 10. Simulasi menggunakan perangkat lunak tertentu digunakan sebagai kontrol, baik pada sisi peledakan dan geotek dari lereng.

\section{B.3. Pengolaha Data Hasil Signature Hole Analysis}

Salah satu cara yang efektif untuk mengontrol tingkat getaran tanah hasil peledakan adalah dengan menggunakan Scaled Distance Analysis yang memungkinkan untuk menentukan jumlah bahan peledak dan jarak yang akan memprediksi secara akurat hasil rambatan gelombang yang akan timbul akibat aktifitas peledakan. 
Konsep Scaled Distance dapat dirumuskan sebagai berikut (Hustrulid, 1999) :

$V=H x\left(D_{s}\right)^{\beta-} \quad D_{s}=D / \sqrt{W}$

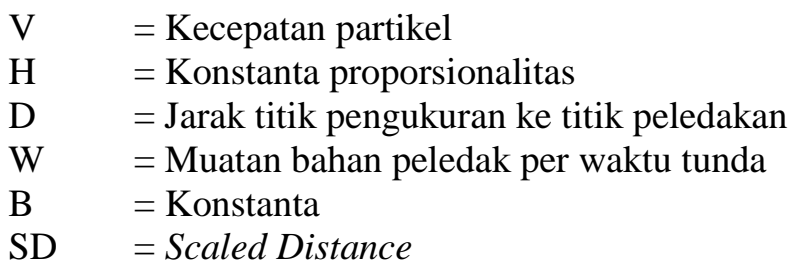

Nilai pada konstanta merupakan nilai yang terkait dengan rambatan gelombang getaran pada medianya, sehingga nilai tersebut menjadi target dalam olah data hasil Signature Hole Analysis. Hasil rekam data yang ditangkap oleh alat pengukur getaran kemudian di unduh dan di proses menggunakan perangkat lunak yang memiliki fitur olah data Signature Hole Analysis dan Scaled Distance

\section{HASIL DAN EVALUASI}

Hasil pengukuran getaran tanah sebelum dilakukan Signature Hole Analysis (Tabel 1.) kemudian di analisis menggunakan Scaled Distance (Gambar 5.) dapat disimpulkan bahwa tikangkat kepercayaan data saat sebelum dilakukan analisis tidak akurat, dibuktikan dengan Coefficient Of Determinant yang diperoleh hanya 0,212 yang berarti tingkat kepercayaan hanya $21,2 \%$.

Tabel 1. Data Pengukuran Getaran Sebelum dilakukan Signature Hole Analysis

\begin{tabular}{|c|c|c|c|c|c|c|c|}
\hline \multirow{3}{*}{ NO } & \multirow{3}{*}{ DATE } & \multirow{2}{*}{ DISTANCE } & \multirow{2}{*}{$\begin{array}{l}\text { CHARGE } \\
\text { WEIGHT }\end{array}$} & \multicolumn{4}{|c|}{ MEASURING DATA } \\
\hline & & & & Transversal & Vertikal & Longitudinal & Airblast \\
\hline & & (m) & $(\mathrm{Kg})$ & $(\mathrm{mm} / \mathrm{s})$ & $(\mathrm{mm} / \mathrm{s})$ & $(\mathrm{mm} / \mathrm{s})$ & $(d B(A))$ \\
\hline 1 & 6 Apr 2019 & 100 & 57 & 16,570 & 8,922 & 23,600 & 130 \\
\hline 2 & 6 Apr 2019 & 100 & 49 & 22,420 & 6,983 & 22,790 & 128 \\
\hline 3 & 7 Apr 2019 & 400 & 51 & 7,251 & 4,934 & 5,100 & 124 \\
\hline 4 & $7 \mathrm{Apr} 2019$ & 400 & 51 & 9,655 & 5,131 & 5,330 & 120 \\
\hline 5 & 7 Apr 2019 & 400 & 51 & 5,202 & 4,185 & 6,321 & 117 \\
\hline 6 & 10 Apr 2019 & 300 & 56 & 7,157 & 5,478 & 9,033 & 124 \\
\hline 7 & $10 \mathrm{Apr} 2019$ & 300 & 56 & 3,421 & 0,851 & 5,194 & 98 \\
\hline 8 & 12 Apr 2019 & 200 & 45 & 5,423 & 4,091 & 5,746 & 122 \\
\hline 9 & $12 \mathrm{Apr} 2019$ & 200 & 45 & 5,943 & 5,249 & 8,772 & 128 \\
\hline 10 & 13 Apr 2019 & 120 & 60 & 27,220 & 18,000 & 27,870 & 127 \\
\hline 11 & 13 Apr 2019 & 100 & 60 & 17,010 & 14,130 & 30,32 & 123 \\
\hline 12 & 15 Apr 2019 & 300 & 50 & 20,443 & 9,616 & 10,390 & 121 \\
\hline 13 & 15 Apr 2019 & 300 & 50 & 11,930 & 8,307 & 13,690 & 122 \\
\hline 14 & $16 \mathrm{Apr} 2019$ & 100 & 43 & 14,060 & 12,690 & 21,690 & 144 \\
\hline 15 & 16 Apr 2019 & 100 & 43 & 13,140 & 11,590 & 12,190 & 134 \\
\hline
\end{tabular}

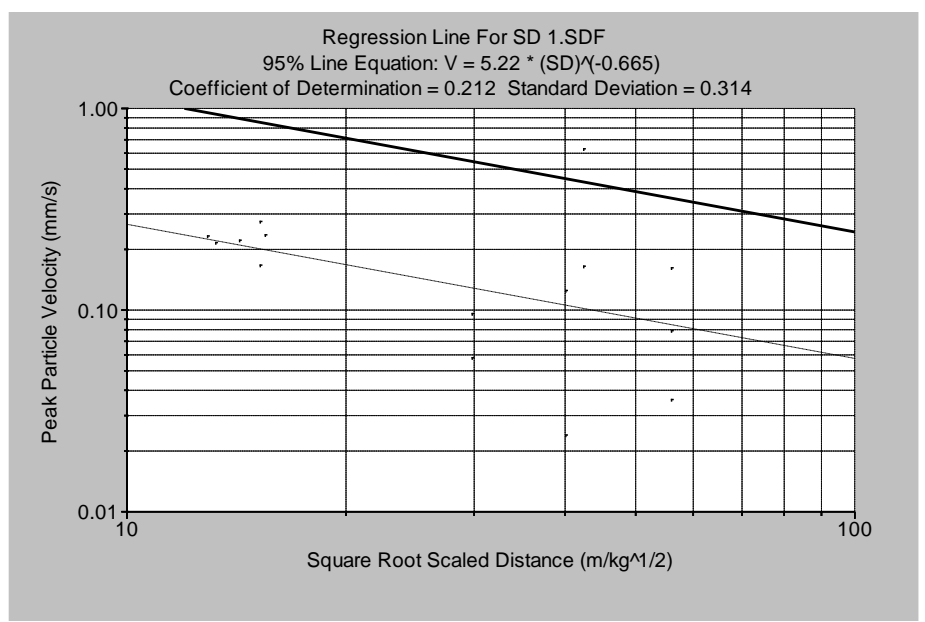

Gambar 5. Sclaed Distance Analysis Sebelum dilakukan Signature Hole Analysis 
Setelah dilakukan percobaan Signature Hole Analysis terdapat trend positif dengan adanya peningkatan Coefficient of Determinan meningkat menjadi 0,864 atau menjadi 86,4\% (Gambar 6. dan Tabel 2.) sehingga prediksi nilai getaran pada area pit 10 dapat menjadi rujukan untuk membuat desain peledakan berikutnya.

Tabel 2. Data Pengukuran Getaran Setelah dilakukan Signature Hole Analysis

\begin{tabular}{|c|c|c|c|c|c|c|c|}
\hline \multirow{3}{*}{ NO } & \multirow{3}{*}{ DATE } & \multirow{2}{*}{ DISTANCE } & \multirow{2}{*}{$\begin{array}{l}\text { CHARGE } \\
\text { WEIGHT }\end{array}$} & \multicolumn{4}{|c|}{ MEASURING DATA } \\
\hline & & & & Transversal & Vertikal & Longitudinal & Airblast \\
\hline & & $(m)$ & $(K g)$ & $(\mathrm{mm} / \mathrm{s})$ & $(\mathrm{mm} / \mathrm{s})$ & $(\mathrm{mm} / \mathrm{s})$ & $(d B(A))$ \\
\hline 1 & 16 Jun 2019 & 168 & 109 & 0,080 & 0,080 & 0,040 & 131 \\
\hline 2 & 16 Jun 2019 & 148 & 111 & 0,100 & 0,110 & 0,070 & 131 \\
\hline 3 & 16 Jun 2019 & 128 & 110 & 0,080 & 0,090 & 0,070 & 131 \\
\hline 4 & 16 Jun 2019 & 108 & 110 & 0,120 & 0,170 & 0,120 & 131 \\
\hline 5 & 16 Jun 2019 & 87 & 110 & 0,230 & 0,200 & 0,240 & 131 \\
\hline
\end{tabular}

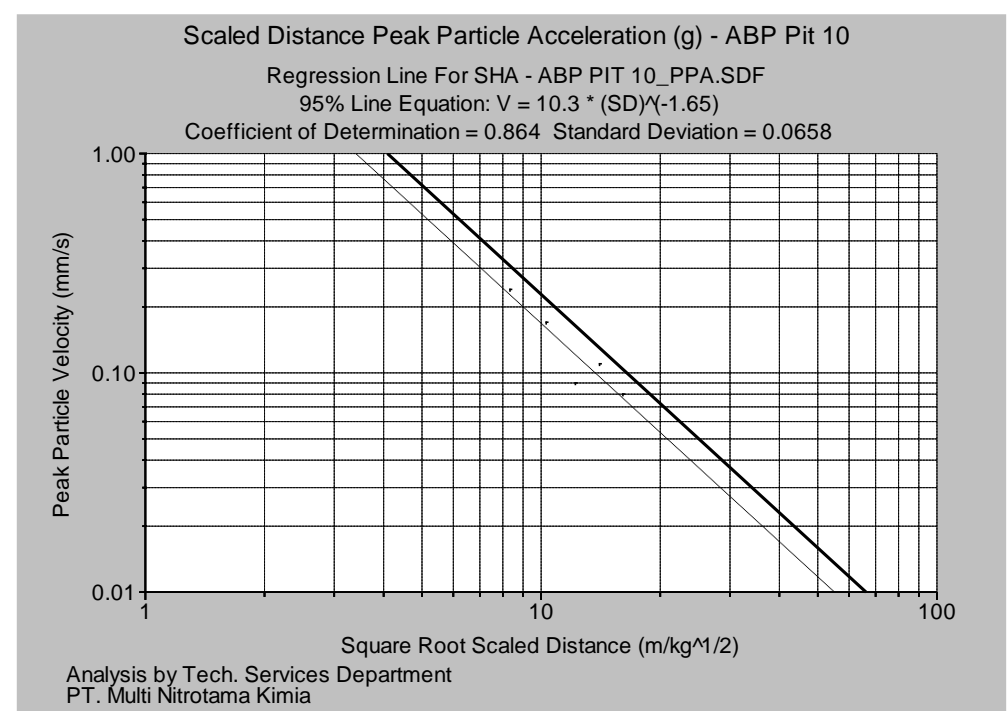

Gambar 6. Sclaed Distance Analysis Setelah dilakukan Signature Hole Analysis

Hasil keluaran yang dihasilkan dari metode Signature Hole Analysis dikombinasikan Scale Distance adalah rekomendasi isian berdasar jarak. Data yang didapat sebelum trial menunjukan bahwa untuk memperoleh nilai PPA (Sesimic Load) 0,07g tidak dapat dilakukan peledakan di area pit 10, sedangkan setelah dilakukan Signature Hole Analysis rekomendasi jarak berdasarkan isian membolehkan peledakan di area pit 10 dengan isian bersadarkan jarak untuk mencapai nilai PPA (Sesimic Load) yang diharapkan yaitu $0,07 \mathrm{~g}$.

Tabel 2. Perbandingan Rekomendasi Isian Berdasar Jarak Sebelum dan Sesudah Trial

\begin{tabular}{|c|c|c|}
\hline \multirow{2}{*}{ Distance (m) } & \multicolumn{2}{|c|}{ Charge Weight (kg) } \\
\cline { 2 - 3 } & Before & After \\
\hline 50 & 0 & 6 \\
\hline 100 & 0 & 24 \\
\hline 150 & 0 & 54 \\
\hline 200 & 0 & 96 \\
\hline 250 & 0 & 150 \\
\hline 300 & 0 & 216 \\
\hline 350 & 0 & 294 \\
\hline 400 & 0 & 384 \\
\hline 450 & 0 & 600 \\
\hline 500 & 0 & 726 \\
\hline
\end{tabular}




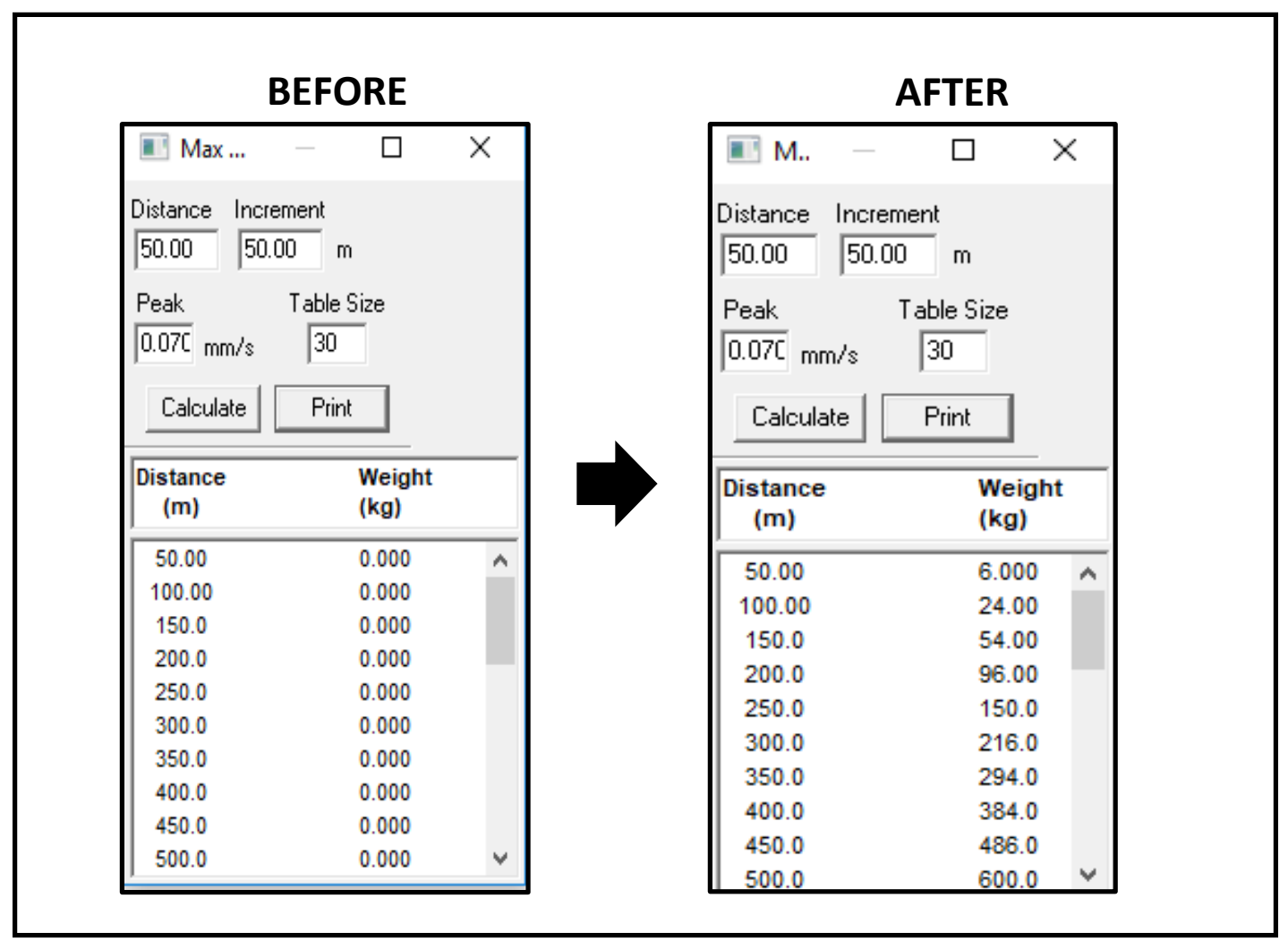

Gambar 6. Perbandingan Rekomendasi Isian Berdasar Jarak Sebelum dan Sesudah Trial

\section{KESIMPULAN}

Berdasarkan proses perbaikan dan evaluasi dari analisa terhadap Ground Vibration yang akan mempengaruhi kestabilan lereng pada pit 10 didapat beberapa kesimpulan yang dijadikan dasar sebagai perbaikan terhadap proses peledakan :

1) Metode Signature Hole Analysis yang dikombinasikan dengan pendekatan Scaled Distance, berhasil menjadi solusi dalam tata kelola getaran peledakan di Pit 10. Hasilnya, sepanjang tahun 2019 berjalan, tidak ada isu berkenaan dengan bagian geotek dari lereng-lereng di seputaran area operasional Pit 10 Tabel 3. Pendekatan Signature Hole Analysis dan kontrol bersama tim Geoteknik menghasilkan kerjasama yang baik serta tata kelola kestabilan lereng menjadi lebih aman.

Tabel 3. Hasil Pemantauan Ground Vibration pada pit 10

\begin{tabular}{|c|c|c|c|c|}
\hline Tanggal & Jarak (meter) & PPV $(\mathrm{mm} / \mathrm{s})$ & Frekuensi $(\mathrm{Hz})$ & $\mathrm{g}(\mathrm{max})$ \\
\hline $10 / 06 / 2019$ & 87 & 117,1 & 6,9 & 0,258622691 \\
\hline $13 / 07 / 2019$ & 240 & 21,88 & 7,9 & 0,055326736 \\
\hline $19 / 07 / 2019$ & 186 & 24,76 & 8,5 & 0,067364363 \\
\hline $26 / 08 / 2019$ & 166 & 18,48 & 16 & 0,044641713 \\
\hline $29 / 08 / 2019$ & 144 & 38,36 & 6,2 & 0,069125635 \\
\hline $30 / 08 / 2019$ & 275 & 13,13 & 5,8 & 0,02437549 \\
\hline $05 / 09 / 2019$ & 363 & 18,66 & 7,6 & 0,045392685 \\
\hline
\end{tabular}


2) Hasil yang positif membuat jarak area peledakan dan isian dapat dioptimalkan sehingga membuat kegiatan peledakan kegiatan operasional yang lain menjadi lebih baik sehingga blasted material dapat ditingkatkan.

3) Peningkatan Coeffiecient of Determinant dari 0,212 menjadi 0,864 menunjukan trend perubahan positif pada Scaled Distance Analysis yang berarti tingkat kepercayaan data meningkat sebesar $65,2 \%$

4) Scaled Distance Database hasil dari Signature Hole Analysis bisa digunakan sebagai rujukan prediksi nilai Peak Particle Acceleration ( $g$ ) pada pit 10

\section{UCAPAN TERIMA KASIH}

Penulis ingin mengucapkan terima kasih kepada PT. Alamjaya Bara Pratama Indonesia sebagai pelanggan PT.Multi Nitrotama Kimia yang memberikan dukungan dan persetujuan mereka untuk menerbitkan makalah ini.

\section{DAFTAR PUSTAKA}

Dowding, C.H. (1985, Blast Vibration Monitoring and Control, England: Routledge

Hustrulid. W. (1999): Blasting Principles for Open Pit Mining, Volume 1. (pp. 272-273). Brookfield: A.A. Balkema. Rotterdam.

. (2010), Blastware Operator Manual Handbook, Instantel Inc., Ottawa, Ontario, Canada, 2010, pp. $6.35-6.58$ 